Acta Cryst. (1988). A44, 767

\title{
The Winners of the First Ewald Medals and Award
}

\author{
By J. C. H. Spence and A. E. Spargo \\ for the Editorial Advisory Committee, \\ J. Gjønnes, F. Fujimoto, A. Bourret, C. J. Humphreys and G. Lempfuhl
}

The award of the first Ewald Prize to J. M. Cowley and A. F. Moodie in 1987 recognizes two of the most influential and creative scientists in diffraction physics during the post-war period.

John Cowley's early interest in diffuse X-ray scattering with B. E. Warren at MIT provided a major contribution to the theory of short-range order in alloys, and established the coefficients which bear their names. Returning to Australia in 1949 to work with Alex Moodie at CSIRO, Cowley launched with Moodie a vigorous programme of theoretical and experimental research into electron diffraction and crystallography, based on the firm conviction that the multiple scattering problem not only was soluble, but also provided new opportunities for extracting structural information from crystals. Their theoretical work on multiple scattering (resulting, with the later commercial availability of computers, in the popular multislice algorithm) and experimental development (with P. Goodman, G. Lempfuhl and others) of the convergent-beam method are characteristic of this period. Later at the School of Physics, Melbourne University, Cowley extended this work into electron imaging and scanning transmission electron microscopy, and began the process of supervising the many students (and grand-students!) who have been inspired by his creativity and tireless dedication to his subject.

Alex Moodie's deep physical insight into all forms of elastic electron scattering at all energies has given us, amongst many other things, a firm foundation for the theory of dynamically forbidden reflections (with J. Gjønnes), a theory of low-energy electron diffraction, and, through his aversion to computation, elegant developments in the theory of few-beam dynamical electron and $\mathrm{X}$-ray diffraction, always emphasizing the symmetries inherent in these problems. At the same time he has relentlessly applied these methods to practical problems of importance in materials physics, notably in the field of ceramics.

John Cowley's move to the Physics Department at Arizona State University in 1970 initiated the growth of the enthusiastic group of young scientists which now, under his guidance, forms the NSF's National US Center for High Resolution Electron Microscopy (HREM). Since then his interests have ranged from the development and application (with S. Iijima) of the methods of atomic resolution transmission electron microscopy, to that of subnanometer coherent electron microdiffraction. His most recent work on imaging and diffraction from crystal surfaces has already had a large impact on the exciting new field of ultra-high-vacuum electron microscopy. In all these areas, John's volatile imagination, infectious enthusiasm and drive have provided both the theoretical basis for understanding new effects, and the means to apply them, particularly to the study of defects in crystals. Cowley's book has also been influential in promoting a unified pedagogical approach to diffraction physics. As Co-editor of this journal for many years, as a member of the IUCr executive, and as director of the NSF HREM facility, Cowley has provided strong and inspiring leadership to all who have worked with him.

Our current knowledge of microcrystallography, disorder and the defect structure of crystals owes a great deal to the work of these two scientists for their early optimistic conviction that the methods of electron crystallography and imaging would some day be useful to crystallographers. The flood of papers in this and other journals on atomic-resolution electron microscopy and electron diffraction in recent years shows that they have been fully vindicated. 


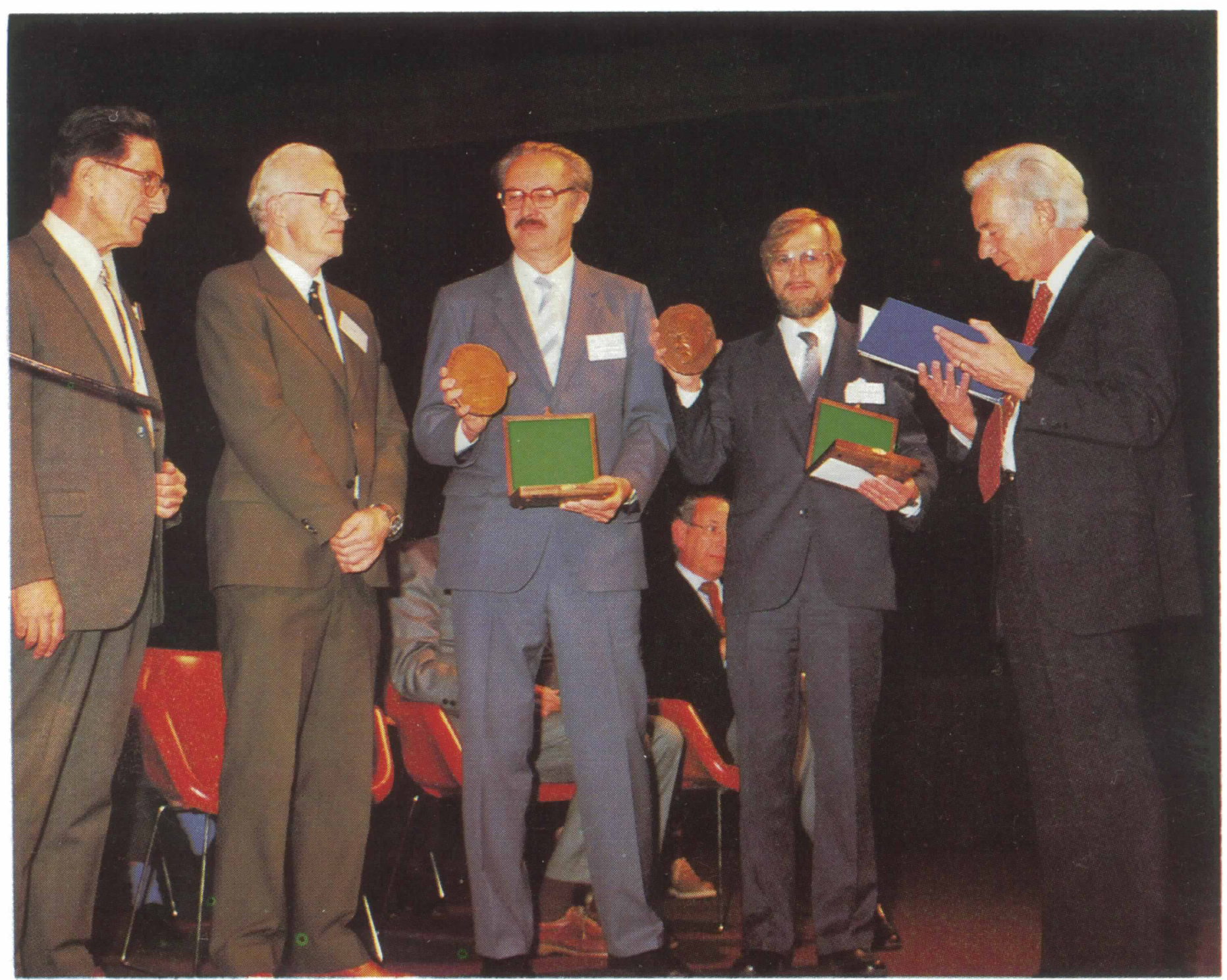

Presentation of the Ewald Medals and Award to Professor J. M. Cowley and Dr A. F. Moodie at the XIV General Assembly and International Congress of Crystallography in Perth, Australia, August 1987.

[Left to right: J. M. Cowley, A. F. Moodie, V. I. Simonov (Vice-President), K. V. J. Kurki-Suonio (General Secretary and Treasurer), Th. Hahn (President)] 